\title{
Airway dynamics in COPD patients by within-breath impedance tracking: effects of continuous positive airway pressure
}

\author{
András Lorx ${ }^{1,2}$, Dorottya Czövek ${ }^{3}$, Zoltán Gingl ${ }^{4}$, Gergely Makan ${ }^{4}$, \\ Bence Radics ${ }^{5}$, Dóra Bartusek ${ }^{2}$, Szabolcs Szigeti $^{2}$, János Gál ${ }^{1}$, \\ György Losonczy², Peter D. Sly ${ }^{3}$ and Zoltán Hantos ${ }^{5,6}$
}

Affiliations: ${ }^{1}$ Dept of Anaesthesiology and Intensive Therapy, Semmelweis University, Budapest, Hungary. ${ }^{2}$ Dept of Pulmonology, Semmelweis University, Budapest, Hungary. ${ }^{3}$ Child Health Research Centre, University of Queensland, Brisbane, Australia. ${ }^{4}$ Dept of Technical Informatics, University of Szeged, Szeged, Hungary. ${ }^{5}$ Dept of Pulmonology, University of Szeged, Szeged, Hungary. ${ }^{6}$ Dept of Medical Physics and Informatics, University of Szeged, Szeged, Hungary.

Correspondence: Zoltán Hantos, Dept of Pulmonology, University of Szeged, 36 Alkotmany str, 6772 Deszk, Hungary. E-mail: hantos.zoltanamed.u-szeged.hu

@ERSpublications

Within-breath changes in mechanics reflect flow limitation, lung inhomogeneity and pressure support impact in COPD http://ow.ly/zjEr306bzDo

Cite this article as: Lorx A, Czövek D, Gingl Z, et al. Airway dynamics in COPD patients by within-breath impedance tracking: effects of continuous positive airway pressure. Eur Respir J 2017; 49: 1601270 [https:// doi.org/10.1183/13993003.01270-2016].

ABSTRACT Tracking of the within-breath changes of respiratory mechanics using the forced oscillation technique may provide outcomes that characterise the dynamic behaviour of the airways during normal breathing.

We measured respiratory resistance $(R \mathrm{rs})$ and reactance $\left(X_{\mathrm{rs}}\right)$ at $8 \mathrm{~Hz}$ in 55 chronic obstructive pulmonary disease (COPD) patients and 20 healthy controls, and evaluated $R$ rs and $X \mathrm{rs}$ as functions of gas flow $\left(V^{\prime}\right)$ and volume $(V)$ during normal breathing cycles. In 12 COPD patients, additional measurements were made at continuous positive airway pressure (CPAP) levels of 4, 8, 14 and $20 \mathrm{hPa}$.

The Rrs and $X_{\mathrm{rs}}$ versus $V^{\prime}$ and $V$ relationships displayed a variety of loop patterns, allowing characterisation of physiological and pathological processes. The main outcomes emerging from the within-breath analysis were the $X_{\mathrm{rs}}$ versus $V$ loop area (AXV) quantifying expiratory flow limitation, and the tidal change in $X \mathrm{rs}$ during inspiration $(\triangle X \mathrm{X})$ reflecting alteration in lung inhomogeneity in COPD. With increasing CPAP, AXV and $\triangle X I$ approached the normal ranges, although with a large variability between individuals, whereas mean Rrs remained unchanged.

Within-breath tracking of Rrs and $X$ rs allows an improved assessment of expiratory flow limitation and functional inhomogeneity in COPD; thereby it may help identify the physiological phenotypes of COPD and determine the optimal level of respiratory support.

This article has supplementary material available from erj.ersjournals.com

Received: June 252016 | Accepted after revision: Nov 082016

Support statement: This study was supported by the Hungarian Scientific Research Fund (grant 105403) and the Australian National Health and Medical Research Council (grant 1002035). Funding information for this article has been deposited with the Open Funder registry.

Conflict of interest: Disclosures can be found alongside this article at erj.ersjournals.com

Copyright OERS 2017 


\section{Introduction}

Although the functional abnormalities in chronic obstructive pulmonary disease (COPD) result from a wide range of structural alterations in the airways and parenchyma, the classification of COPD still relies on the combination of the measures of a simple forced expiratory flow-volume manoeuvre and symptom severity [1]. Spirometry correlates poorly with respiratory symptoms and quality of life [2]; it cannot differentiate between mechanisms of airway obstruction, and the severity of COPD can be both underand overestimated based on forced expiratory volume in $1 \mathrm{~s}$ (FEV1) values [3]. These limitations indicate the need for sensitive non-invasive lung function tests to explore the mechanical contributors of low lung function in COPD, including the presence of expiratory flow limitation (EFL) during tidal breathing [4]

The forced oscillation technique (FOT) determines the mechanical impedance of the respiratory system (Zrs) by using small-amplitude external driving signals of single or multiple frequencies, typically superimposed on the signals of spontaneous breathing. $Z \mathrm{rs}$ is conventionally represented in terms of the resistance $(R \mathrm{rs})$ and reactance $(X \mathrm{rs})$ of the respiratory system. Rrs characterises the dissipative processes in the airways and the tissues, whereas $X_{\mathrm{rs}}$ reflects the balance between the energy-storing properties of elastance and inertance, as functions of oscillation frequency [5]. The FOT is acknowledged for its effort independence and the low cooperation requirement; these features have made the FOT a promising method of lung function measurement in $\operatorname{COPD}[3,6,7]$. Since early work $[8,9]$ has demonstrated that in COPD there are marked differences in the mechanical properties within a respiratory cycle, the ability of the FOT to follow short-term changes in Rrs and $X_{\mathrm{rs}}$ [10-13] makes this method particularly suitable for a better characterisation of abnormal lung function. Indeed, Dellacà et al. [12] proposed an index for EFL, calculated as a difference between the average inspiratory and expiratory $\mathrm{X}$ rs values, as the latter suddenly fall to large negative values when EFL develops; it has also been demonstrated that the EFL index can support the selection of the level of nasal continuous positive airway pressure (CPAP) [11]. The calculation of the mean values of $X_{\mathrm{rs}}$ separately for the inspiratory and expiratory phases has been employed subsequently in various studies to assess the presence of EFL [14-18].

While EFL is one of the main features of COPD, there are other mechanical abnormalities in this disease that may be masked by the presence of EFL during tidal breathing or forced expiratory manoeuvre. Therefore, in the present study we aimed to characterise both EFL and the flow-independent mechanical properties of the respiratory system in patients with COPD, using a novel arrangement of the FOT [10]. We hypothesised that 1) the pattern of looping in expiratory Xrs during tidal breathing would reflect the presence and degree of EFL; 2) analysis of the inspiratory phase would provide information on the inhomogeneous mechanical behaviour of the lungs; and 3) the within-breath outcome variables would change with the application of CPAP, and thus help determine the optimal CPAP setting in individual COPD patients.

\section{Materials and methods \\ Subjects}

Patients admitted to the Department of Pulmonology at Semmelweis University (Budapest, Hungary) with an acute exacerbation of COPD were eligible to participate in the study. Informed consent was obtained, clinical data were collected and lung function tests were performed within $48 \mathrm{~h}$ of admission. Age-matched healthy controls were recruited from the staff in the participating institutions. The study was approved by the local ethical committee of Semmelweis University, in agreement with the scientific and human research ethics committee of the Hungarian Medical Research Council.

\section{Lung function}

Forced expiratory flow-volume data were measured using the PDD-301 spirometer (Piston Medical, Budapest, Hungary) according to the American Thoracic Society/European Respiratory Society guidelines [19]. Zrs was measured using a custom-made FOT setup (online supplementary figure S1) consisting of a wave-tube for the estimation of $Z_{r s}$ as the load impedance [20], a screen pneumotachograph for the recording of the tidal flow $\left(V^{\prime}\right)$ and a loudspeaker for the generation of the forced oscillatory signal. Volume $(V)$ was obtained via numerical integration of $V^{\prime}$. A sinusoidal signal with a frequency of $8 \mathrm{~Hz}$ and an amplitude of $<0.3 \mathrm{hPa}$ was superimposed on spontaneous breathing for $24 \mathrm{~s}$. Three recordings were collected and the one with the most even breathing pattern was selected for within-breath analysis. In a subgroup of COPD patients, additional measurements were made at elevated airway pressures of 4, 8, 14 and $20 \mathrm{hPa}$, generated by a CPAP device (Trilogy 100; Philips Respironics, Murrysville, PA, USA).

\section{Data analysis}

The auto- and cross-correlation spectra of the wave-tube pressures were computed using a fast Fourier transform algorithm, and a bandwidth of $\pm 2 \mathrm{~Hz}$ around the $8-\mathrm{Hz}$ oscillation signal frequency was considered for further analysis. The $Z$ rs values were computed for each oscillation period $(0.125 \mathrm{~s})$ and the 
TABLE 1 Definition of the impedance and tidal breathing variables

\begin{tabular}{|c|}
\hline$R_{\text {mean }}\left(X_{\text {mean }}\right)$ \\
\hline$R_{\text {meanE }}\left(X_{\text {meanE }}\right)$ \\
\hline$R_{\text {meanl (XmeanI) }}$ \\
\hline EFL index \\
\hline $\operatorname{ReE}(X \mathrm{eE})$ \\
\hline Rel (Xel) \\
\hline$\Delta X$ \\
\hline$X_{\min }$ \\
\hline AXV \\
\hline$V^{\prime} \max E$ \\
\hline$V^{\prime} \operatorname{maxl}$ \\
\hline$T E$ \\
\hline Ttot \\
\hline TPTEF \\
\hline
\end{tabular}

Mean resistance (reactance) during total breaths Mean expiratory resistance (reactance) Mean inspiratory resistance (reactance) Xmeanl - Xmeanl

Resistance (reactance) at end-expiration Resistance (reactance) at end-inspiration $X \mathrm{eE}-X_{\mathrm{el}}$

Minimum expiratory reactance

Area within the reactance versus volume loops Maximum expiratory flow

Maximum inspiratory flow

Expiratory time

Breathing period

Expiratory time until peak expiratory flow

\#: defined by Dellacè et al. [12].

different phases of the breathing cycle (and the corresponding Rrs and Xrs values) were identified. The tidal breathing and the within-breath $Z$ rs variables are summarised and defined in table 1 and online supplementary figure S2.

\section{Statistical analysis}

Data are presented as median (interquartile range). Spirometric variables are presented as $\mathrm{Z}$-scores using the Global Lungs Initiative 2012 equations. To assess the difference in the data between healthy subjects and COPD patients the Wilcoxon rank-sum test was applied. Relationships between independent lung

TABLE 2 Comparison of lung function measures between healthy subjects and chronic obstructive pulmonary disease (COPD) patients

\begin{tabular}{|c|c|c|c|}
\hline & Healthy & COPD & p-value \\
\hline Subjects & 20 & 55 & \\
\hline Age years & $60(52-64)$ & $62(56-69)$ & 0.34 \\
\hline Males & 9 & 22 & NS \\
\hline FEV $1 / F V C$ & $0.76(0.71-0.79)$ & $0.44(0.39-0.55)$ & $<0.001$ \\
\hline FEV1/FVC z-score & $-0.43(-0.89--0.08)$ & $-4.00(-4.36--2.82)$ & $<0.001$ \\
\hline FEV1 L & $2.97(2.45-3.43)$ & $0.75(0.641-0.95)$ & $<0.001$ \\
\hline FEV 1 z-score & $-0.08(-0.61-0.54)$ & $-4.38(-4.87--3.72)$ & $<0.001$ \\
\hline$V$ T $\mathrm{mL}$ & 629 (506-953) & $758(614-960)$ & 0.28 \\
\hline$T E / T$ tot & $0.56(0.53-0.58)$ & $0.63(0.60-0.66)$ & $<0.001$ \\
\hline TPTEF/TE & $0.32(0.22-0.36)$ & $0.20(0.16-0.29)$ & $<0.001$ \\
\hline$V_{\text {maxE}}^{\prime} / V^{\prime} \max \mid$ & $0.88(0.73-1.0)$ & $0.74(0.6-0.86)$ & $<0.001$ \\
\hline$R_{\text {mean }} \mathrm{hPa} \cdot \mathrm{S} \cdot \mathrm{L}^{-1}$ & $3.15(2.79-3.49)$ & $5.13(4.26-6.18)$ & $<0.001$ \\
\hline$R_{\text {meanE }} \mathrm{hPa} \cdot \mathrm{S} \cdot \mathrm{L}^{-1}$ & 3.27 (2.79-3.93) & $5.42(4.13-6.75)$ & $<0.001$ \\
\hline Rmeanl hPa.S. $\mathrm{L}^{-1}$ & $2.88(2.30-3.27)$ & $4.67(4.05-5.87)$ & $<0.001$ \\
\hline ReE hPa.s.L $\mathrm{L}^{-1}$ & $2.34(2.07-2.78)$ & $5.43(4.48-6.74)$ & $<0.001$ \\
\hline Rel hPa.s. $\mathrm{L}^{-1}$ & $1.99(1.69-2.32)$ & $3.25(2.58-4.11)$ & $<0.001$ \\
\hline Xmean $\mathrm{hPa} \cdot \mathrm{S} \cdot \mathrm{L}^{-1}$ & $0.11(-0.31-0.27)$ & $-5.18(-6.83--3.61)$ & $<0.001$ \\
\hline XmeanE hPa.s. $\mathrm{L}^{-1}$ & $0.13(-0.30-0.23)$ & $-6.72(-8.50--4.22)$ & $<0.001$ \\
\hline Xmeanl $\mathrm{hPa} \cdot \mathrm{s} \cdot \mathrm{L}^{-1}$ & $0.07(-0.2-0.26)$ & $-2.63(-3.37--1.67)$ & $<0.001$ \\
\hline$X_{e E} \mathrm{hPa} \cdot \mathrm{s} \cdot \mathrm{L}^{-1}$ & $0.29(0.11-0.48)$ & $-4.89(-6.43--3.41)$ & $<0.001$ \\
\hline Xel hPa.s. $\mathrm{L}^{-1}$ & $-0.04(-0.32-0.14)$ & $-1.58(-2.30--1.05)$ & $<0.001$ \\
\hline$\Delta X \mathrm{hPa} \cdot \mathrm{s} \cdot \mathrm{L}^{-1}$ & $0.29(0.24-0.49)$ & $-3.03(-4.47--1.97)$ & $<0.001$ \\
\hline$X_{\min } \mathrm{hPa} \cdot \mathrm{s} \cdot \mathrm{L}^{-1}$ & $-0.50(-88--0.13)$ & $-9.19(-11.99--6.44)$ & $<0.001$ \\
\hline AXV hPa.s & $0.00(-0.09-0.09)$ & $2.34(1.32-3.05)$ & $<0.001$ \\
\hline $\mathrm{EFL}$ index $\mathrm{hPa} \cdot \mathrm{s} \cdot \mathrm{L}^{-1}$ & $-0.01(-0.13-0.10)$ & $3.24(2.09-5.51)$ & $<0.001$ \\
\hline
\end{tabular}

Data are presented as $\mathrm{n}$ or median (interquartile range), unless otherwise stated. $\mathrm{FEV} 1$ : forced expiratory volume in $1 \mathrm{~s}$; FVC: forced vital capacity; VT: tidal volume; NS: nonsignificant. Lung function variables are defined in table 1. 
function variables were assessed using multiple linear regression, including height, sex and weight as covariables. The effect of the different CPAPs on the FOT variables was analysed using one-way repeated measures ANOVA.

\section{Results}

55 patients were recruited and the severity of their COPD classified according to the Global Initiative for Chronic Obstructive Lung Disease (GOLD) spirometric classification [21] as stage $2(n=8)$, stage $3(n=24)$ and stage $4(\mathrm{n}=23)$. The ages of subjects in the COPD and healthy groups were similar: $60.5(52.8-67.0)$ years versus $62.0(56.0-69.0)$ years; $\mathrm{p}=0.64$. FOT data were collected for all participants, while four patients with GOLD stage 4 were not able to perform valid spirometry. A summary of the spirometry and FOT data is presented in table 2; with the exception of tidal volume, all measures were significantly different between the two groups.

\section{Changes in Zrs with tidal breathing}

Figures 1 and 2 illustrate typical changes in $Z$ rs with tidal volume and $V^{\prime}$ in representative healthy subjects and patients with COPD; the Zrs loops of all healthy and COPD subjects are presented in online supplementary figures S3 and S4, respectively. In healthy subjects (figure 1), the within-breath changes in Rrs were much larger than in $X$ rs and were dominated by the $V^{\prime}$ dependence, which was of different degrees between subjects and generally more marked in expiration. $X \mathrm{rs}$ did not change with $V^{\prime}$, and the values for mean expiratory $(X$ meanE) and inspiratory $(X$ meanI) reactance were similar $(\mathrm{p}=0.35$; table 2$)$. However, $X_{\mathrm{r} s}$ decreased with $V$ (i.e. from reactance at end-expiration $\left(X_{\mathrm{eE}}\right)$ to reactance at end-inspiration $(X \mathrm{II}))$ in all healthy subjects $(\mathrm{p}<0.001$, figure 3 and table 2$)$.
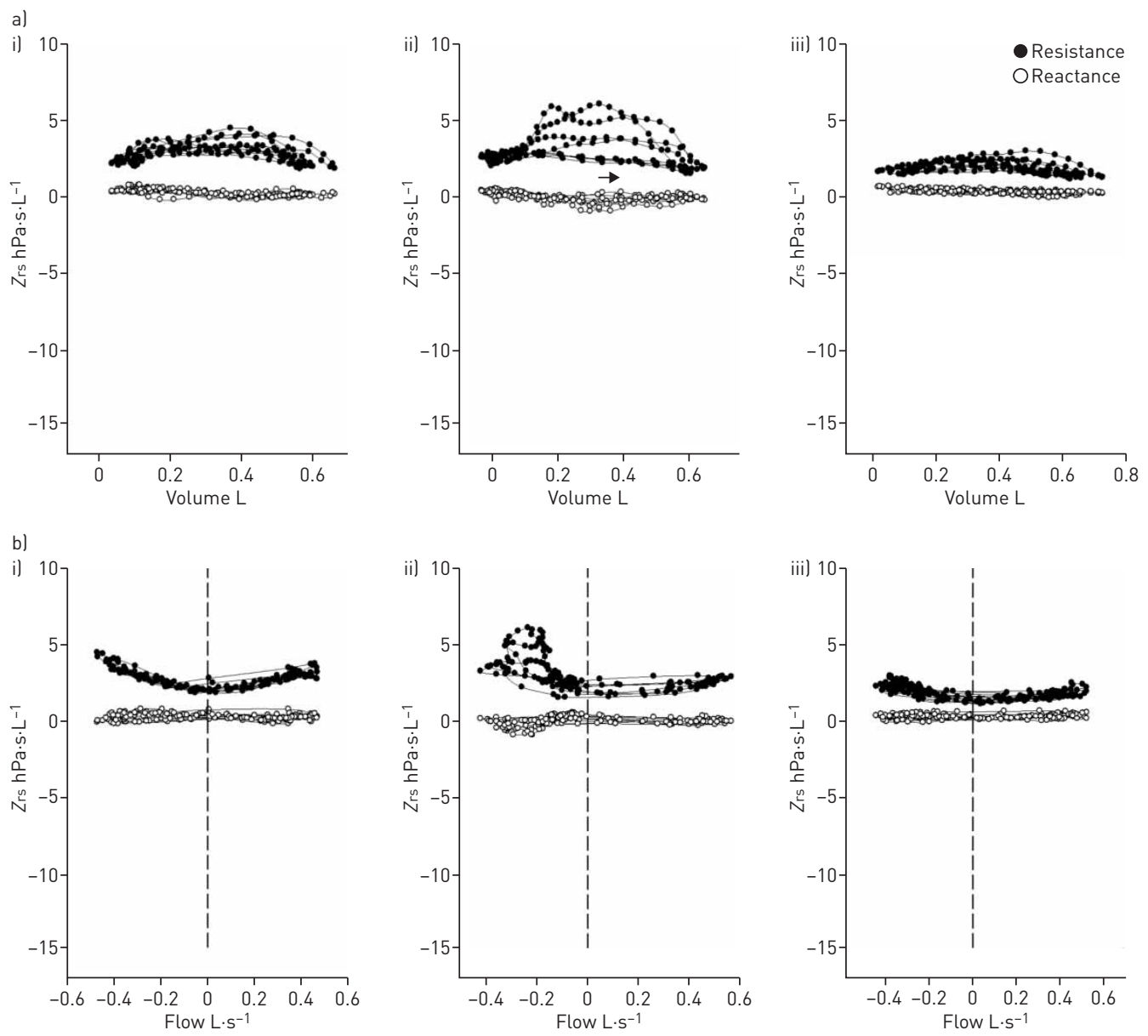

FIGURE 1 Representative respiratory system impedance (Zrs) versus al volume and b) flow loops recorded in three healthy subjects show typical i) increases in resistance with inspiratory and expiratory flow, ii) linear behaviour in inspiration with marked expiratory breaking (arrow indicates the inspiratory limb) and iii) mild flow dependence throughout the breathing cycle. Note the minimal changes in reactance during the breathing cycle. 

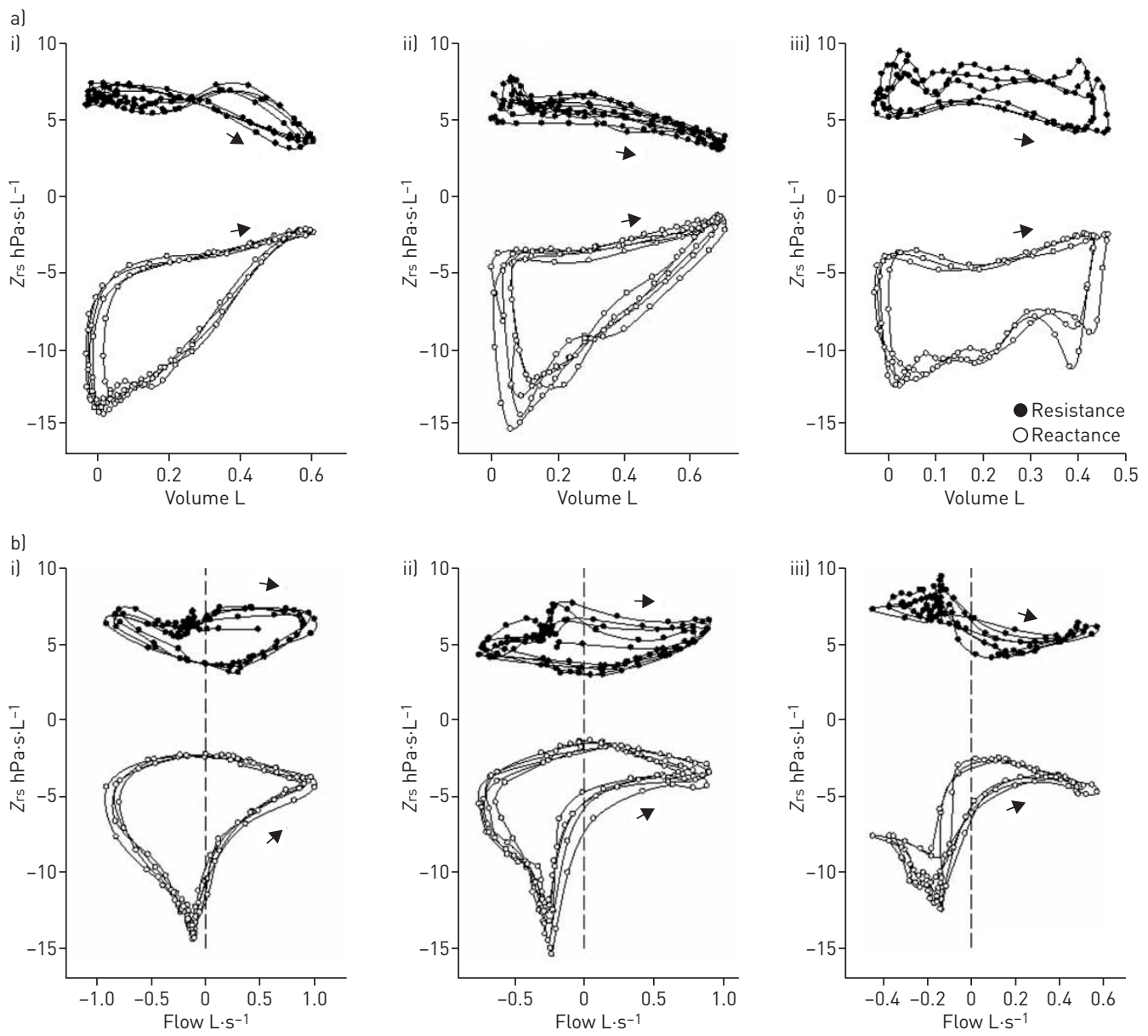

FIGURE 2 Representative respiratory system impedance (Zrs) versus a) volume and b) flow loops recorded in three chronic obstructive pulmonary disease patients. Arrows mark the inspiratory limbs and direction. Note the different patterns of the development of expiratory flow limitation (EFL): i) onset of $E F L$ at $\sim 80 \%$ tidal volume, ii) gradual development of EFL from the beginning of expiration, iii) almost full EFL at the start of expiration.

While the mean values of Rrs were higher in the COPD patients than in the healthy subjects (table 2), the peak-to-peak changes relative to the corresponding mean values within the inspiratory and expiratory phases were similar in the two groups (63\% versus $64 \%$, respectively, for inspiration, $\mathrm{p}=0.57$ and $67 \%$ versus $69 \%$, respectively, for expiration, $\mathrm{p}=0.41)$. In contrast, the more negative $X$ mean values observed in the COPD patients (table 2) were associated with a marked looping in the Xrs versus $V$ diagram (figure 2 and online supplementary figure S4). The separation of the expiratory and inspiratory limbs observed in the $X_{\mathrm{rs}}$ versus $V$ diagrams in almost all COPD patients resulted in significantly higher values of area within the reactance versus volume loops (AXV) and EFL index than that of the healthy subjects (table 2). We

FIGURE 3 a) Individual changes in respiratory system reactance $\left(X_{\mathrm{rs}}\right)$ values between end-expiration $(X \mathrm{eE})$ and end-inspiration ( $\left.X_{\mathrm{el}}\right)$ and $\left.\mathrm{b}\right)$ their differences $\left(\Delta X_{\mathrm{I}}=X_{\mathrm{e}} \mathrm{E}-X_{\mathrm{el}}\right)$ in healthy and chronic obstructive pulmonary disease (COPD) subjects. Note the different signs of the $\Delta X_{1}$ values in healthy $\left(X_{\mathrm{e} E}-X_{\mathrm{el}}>0\right)$ and COPD $\left(X_{\mathrm{e} E}-X_{\mathrm{el}}<0\right)$ subjects.
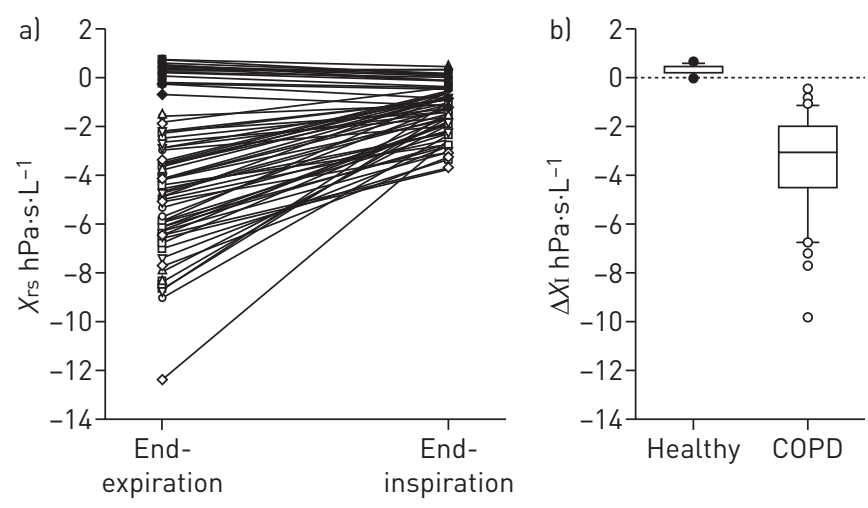
note here that since the EFL index can be considered as a rectangular approximation of AXV (online supplementary figure $\mathrm{S} 1)$, the two quantities are strongly correlated $\left(\mathrm{r}^{2}=0.79\right)$.

$X \mathrm{rs}$ exhibits a variety of looping patterns between individuals with COPD (online supplementary figure S3). The typical Zrs loops from representative COPD patients (figure 2) illustrate different timings of flow limitation, but correspond to similar EFL indices $\left(5.50-5.62 \mathrm{hPa} \cdot \mathrm{s} \cdot \mathrm{L}^{-1}\right)$.

Note that the inspiratory limbs of $X_{\mathrm{rs}}$ are markedly different from that of the healthy subjects: they uniformly increase between the beginning and the end of inspiration $(p<0.001$; figure $3 a$ and table 2$)$, and this results in a negative value for $\Delta X_{\mathrm{I}}$ (defined as $\Delta X_{\mathrm{I}}=X_{\mathrm{eE}}-X_{\mathrm{eI}}$ ) in all of the COPD patients (figure $3 \mathrm{~b}$ ). Importantly, $\Delta X I$ was found to be unrelated to AXV in the COPD patients $(r=0.29, p=0.21)$.

\section{Relationship between lung function measured during tidal breathing and forced expiration}

There was no correlation between the FEV1 z-score and AXV ( $\mathrm{r}=0.07, \mathrm{p}=0.61)$ and $\Delta X \mathrm{XI}(\mathrm{r}=0.08, \mathrm{p}=0.60)$. In addition, the FEV1 $\mathrm{z}$-score was unrelated to the tidal breathing trimming indices $(\mathrm{r}=0.16, \mathrm{p}=0.27$ for expiratory time $(T \mathrm{E}) / \mathrm{breathing}$ period; $\mathrm{r}=0.20, \mathrm{p}=0.16$ for expiratory time until peak expiratory flow/ $\mathrm{TE}$ and $\mathrm{r}=0.11, \mathrm{p}=0.43$ for maximum expiratory flow/maximum inspiratory flow.

\section{Effects of CPAP}

Measurements were performed during increasing CPAP in 12 patients with COPD. The $Z$ rs loops recorded in a representative patient at increasing levels of CPAP illustrate the progressive decrease of AXV (figure 4). In this patient, the application of $8 \mathrm{hPa}$ eliminated almost all looping in the $X_{\mathrm{rs}}$ versus $V$ relationship. As highlighted by the zero-flow values in the $X_{\mathrm{rs}}$ versus $V^{\prime}$ plots, the positive volume dependence in $X$ rs also disappeared on reaching this CPAP level. The levels of CPAP required to reduce AXV and return $\triangle X I$ to positive values varied considerably between patients (figure 5). The finding that the individual changes in AXV and $\triangle X I$ with CPAP were either simultaneous or dissociated is also illustrated in online supplementary figure S6. The improvement in $\triangle X I$ with CPAP was a result of the increasing values of $\mathrm{XeE}$, as CPAP had no effect on the values of $\mathrm{XeI}$ (figure 5). The rest of the reactance measures $(X$ mean, AXV and $\triangle X I)$ exhibited strong dependence on CPAP $(p<0.001)$ and they approached
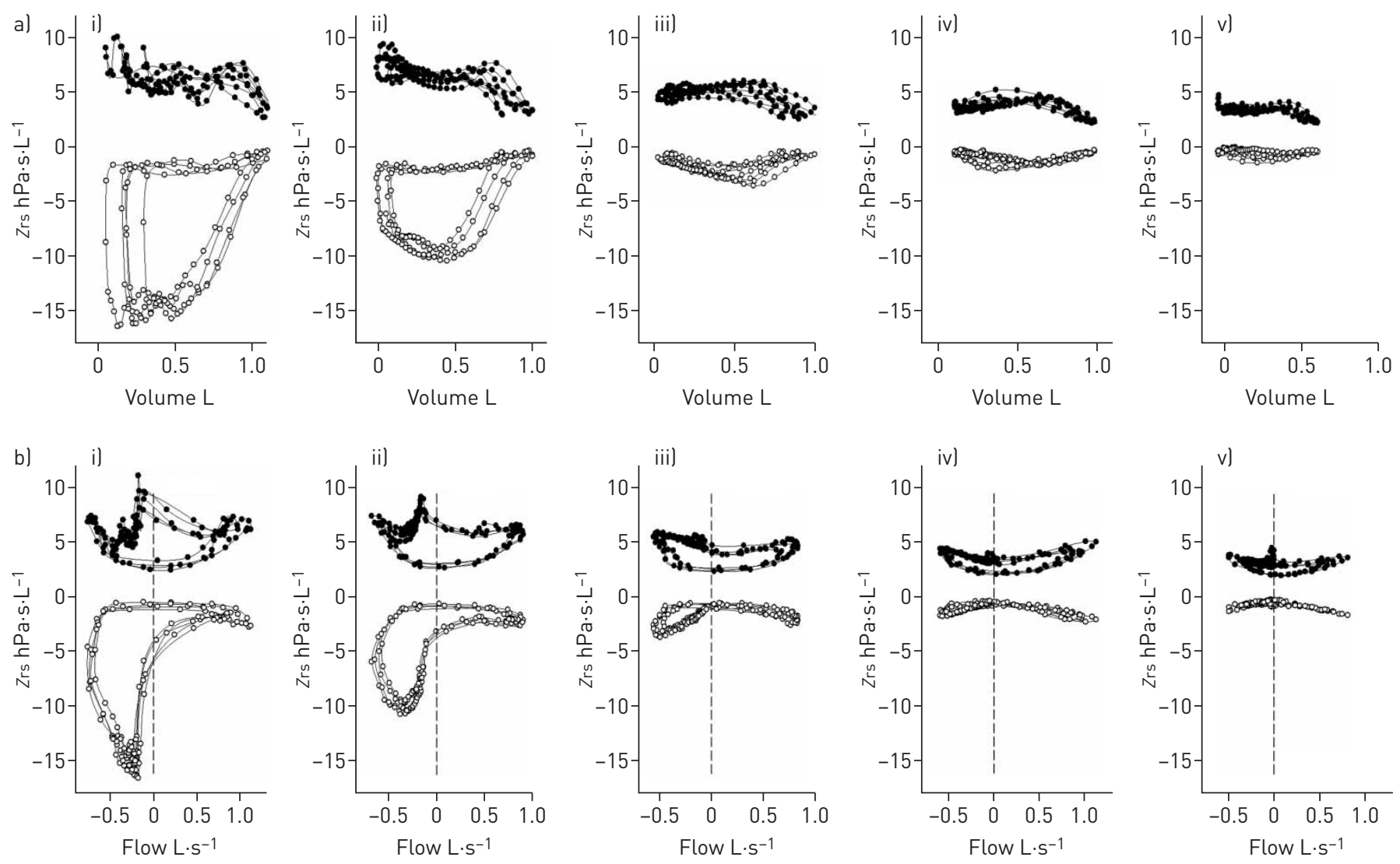

FIGURE 4 Tracings of respiratory impedance ( $\mathrm{rs}$ ) plotted against a) volume and b) flow at increasing levels of continuous positive airway pressure in a representative chronic obstructive pulmonary disease patient. i) $0 \mathrm{hPa}$; ii) $4 \mathrm{hPa}$; iii) $8 \mathrm{hPa}$; iv) $14 \mathrm{hPa}$; v) $20 \mathrm{hPa}$. 

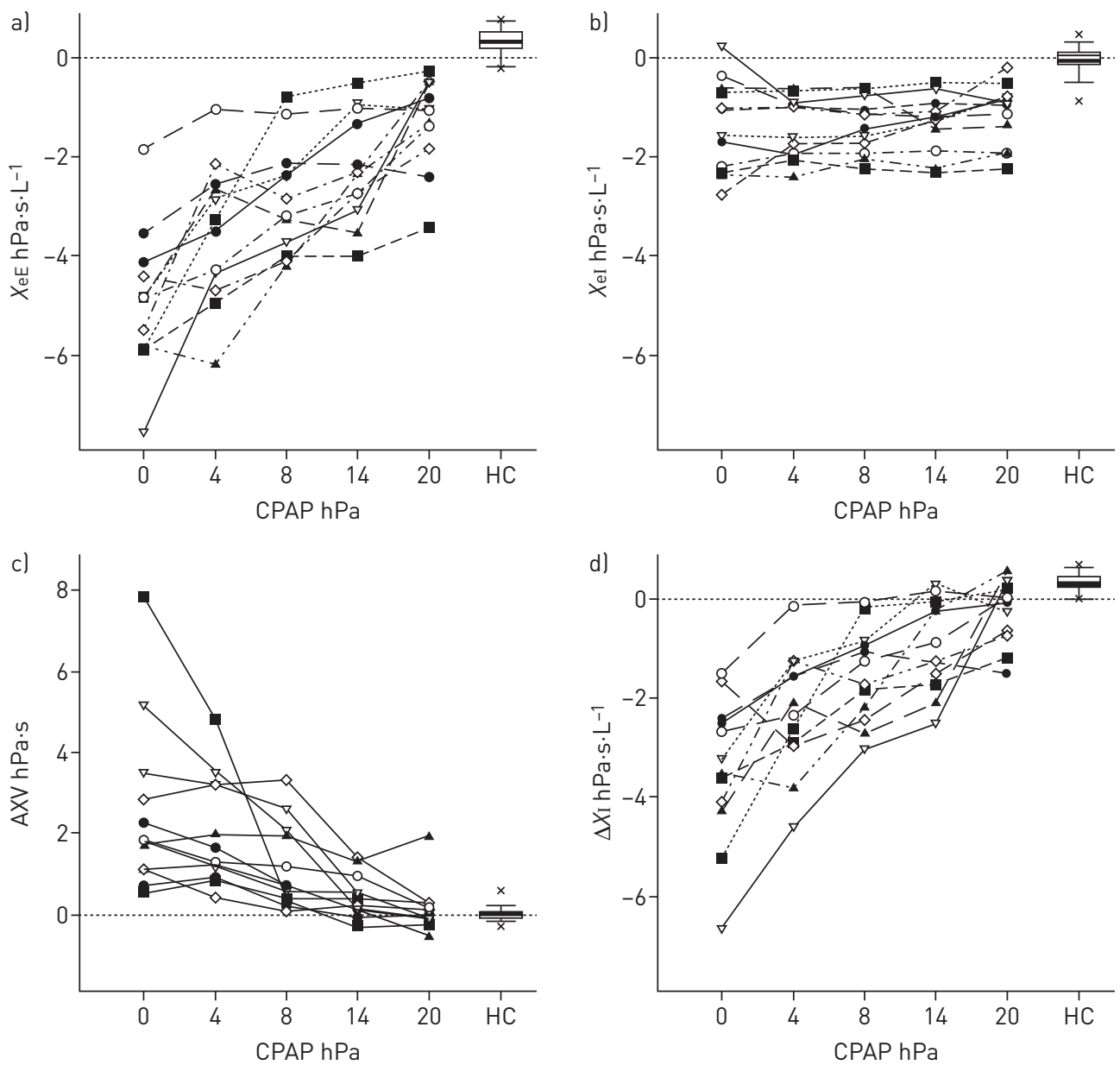

FIGURE 5 Reactance measures as functions of continuous positive airway pressure (CPAP) in individual chronic obstructive pulmonary disease patients. Box plots represent data obtained in healthy controls $(\mathrm{HC})$ at baseline. Reactance at a) end-expiration ( $\left.X_{\mathrm{eE}}\right)$ and $b$ ) end-inspiration $\left.\left(X_{\mathrm{el}}\right) ; \mathrm{c}\right)$ area within the reactance versus volume loops (AXV); d) difference in reactance between end-expiration and end-inspiration $\left(\Delta X_{I}\right)$.

the normal values with increasing pressure; however, their 20 -hPa values remained significantly different from the values of healthy controls, with the exception of AXV ( $p=0.15)$, suggesting the complete elimination of EFL at this pressure. Mean resistance during total breaths was independent of CPAP $(\mathrm{p}=0.057)$; while resistance at end-expiration still displayed a decreasing tendency with CPAP $(\mathrm{p}=0.015)$, the pressure dependence disappeared at end-inspiration $(\mathrm{p}=0.445)$. All resistance values at $20 \mathrm{hPa}$ remained significantly higher than the corresponding values of the healthy subjects measured at zero CPAP ( $\mathrm{p}<0.001$, online supplementary figure S7).

\section{Discussion}

The present study was undertaken to track dynamic changes of respiratory mechanics within the breathing cycle in healthy subjects and patients with COPD, in an attempt to characterise the alterations in respiratory mechanics via the dependences of Rrs and $X$ rs on tidal flow and volume. The Xrs versus $V$ loops exhibited a variety of patterns and degrees of impairment in expiratory mechanics in individuals with COPD; they help to identify where EFL appears and to what extent it develops in tidal expiration. Additionally, the trend in $X \mathrm{rs}$ during inspiration reflects changes in lung inhomogeneity, another functional abnormality present in COPD. We have also confirmed that these measures of Xrs obtained during tidal breathing detect the effects of positive airway pressure support on respiratory mechanics.

Our data are in accordance with earlier qualitative observations [8, 22-24] on the marked nonlinearities involved in the mechanics of the total respiratory system during normal breathing. While COPD patients exhibited elevated Rrs values when compared to healthy controls, in agreement with earlier findings [3, 6, 22, 25], the relative within-breath changes in Rrs were substantial both in the COPD patients and healthy controls. This suggests that the upper airways (and the vocal cords in particular) exhibiting nonlinear, i.e. 

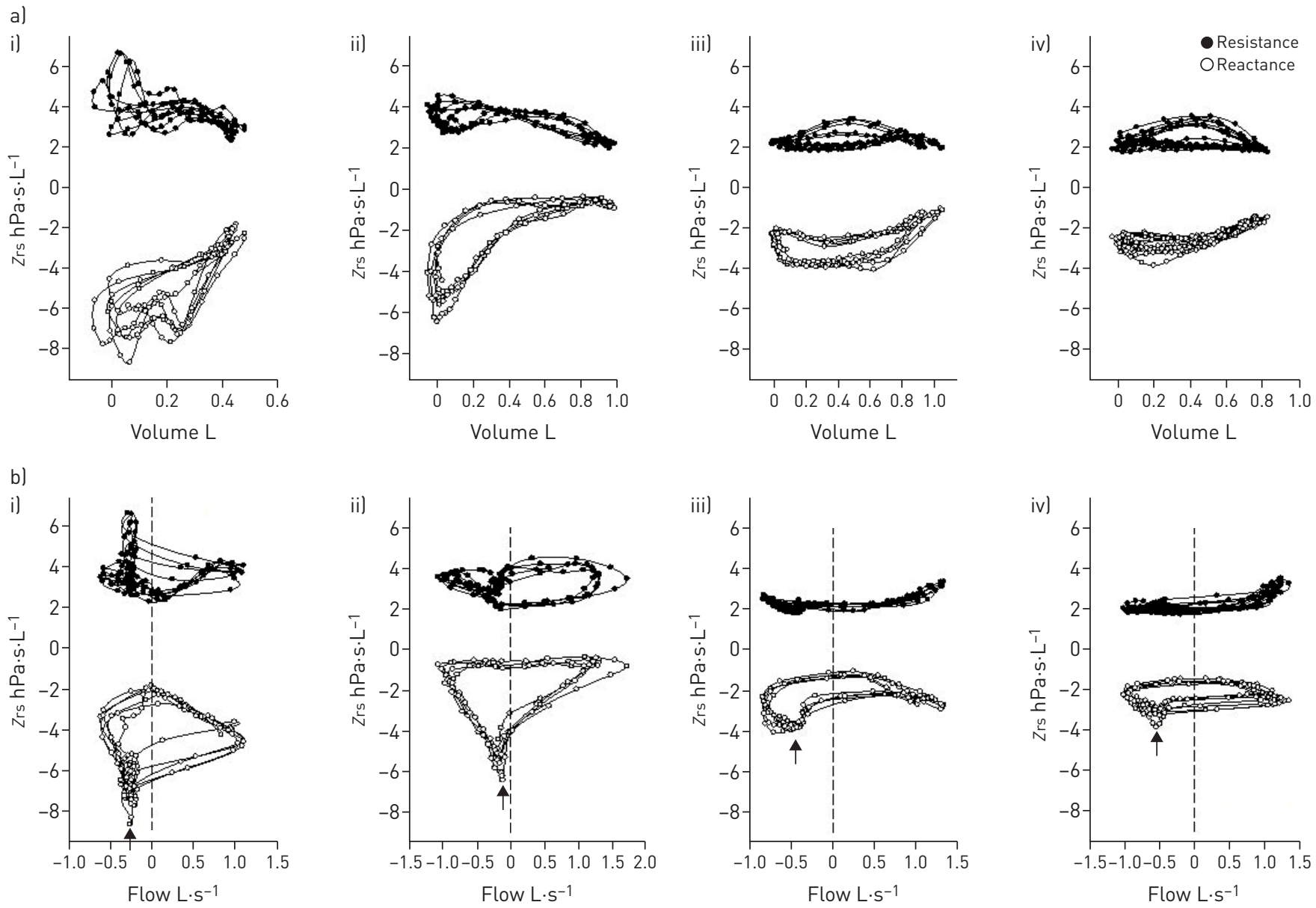

FIGURE 6 Examples of impedance (Zrs) versus a) volume and b) flow loops in four different chronic obstructive pulmonary disease (COPD) patients who exhibit variable or low values of the expiratory flow limitation (EFL) index. Arrows point to decreasing reactance values gathering at levels of limited expiratory flow. i) Swings in expiratory reactance and variable release from EFL on inspiration result in a wide range of the EFL index (2.05-2.95); ii) development of EFL delayed until mid-expiration (mean EFL index 2.04); iii and iv) low-impedance COPD patients with iii) clear looping (EFL index 1.19) or iv) minimal looping in the reactance versus volume plot (EFL index 0.49), but with possible signs of flow limitation.

flow-dependent resistance during both expiration and inspiration are important contributors to the flow-related fluctuations in $R \mathrm{rs}[8,24]$. The large cyclic variations in $X_{\mathrm{rs}}$ in the COPD patients, attributed mostly to EFL, are in contrast with the mild, yet consistently negative, dependence on $V$ observed in healthy subjects.

In addition, the weak or lacking relationships between FEV1 and the degree of flow limitation manifested during tidal breathing $[3,14]$ demonstrated in the present study suggest that the EFL inferred from a forced expiratory manoeuvre does not reflect the alterations in lung function during normal breathing. Alternative techniques, such as application of negative expiratory pressure [26], the abdominal compression method [27] and the FOT [12] have been introduced for the detection of EFL during breathing. DeLLACÀ et al. [12] proposed an EFL index based on FOT variables (i.e. XmeanI-XmeanE at $5 \mathrm{~Hz}$ ) and simultaneous measurements of transpulmonary mechanics, in order to distinguish flow-limited breaths from "nonflow-limited" ones, although with the reservation that the oesophageal pressure measurement method may also fail as a gold standard to identify the EFL breaths. While the EFL index can reflect the presence of flow limitation, the fact that its calculation is based on mean $\mathrm{Xrs}$ values in expiration and inspiration limits further insight into the underlying mechanisms or the development of EFL. Indeed, patients with different patterns of flow limitation that develop in different phases of the expiration can have very similar EFL indices (figure 2). Additionally, our measurements demonstrate that the looping characteristics in the Xrs versus $V$ and $V^{\prime}$ diagrams (figure 6) are preserved, while the EFL index decreases well below the optimal threshold defined in [12] as $2.8 \mathrm{hPa} \cdot \mathrm{s} \cdot \mathrm{L}^{-1}$.

Of particular interest are the measurements in patients whose Rrs values are within the normal range, but whose moderately negative $X_{\mathrm{rs}}$ values exhibit looping in the $X_{\mathrm{rs}}$ versus $V$ graphs. The gathering of data 
points at low rates of expiratory $V^{\prime}$ when $X_{\mathrm{rs}}$ tends to the minimum expiratory reactance (figure 6) can also be a signature of EFL. The Zrs data obtained during normal breathing in these GOLD stage 3 and 4 patients may indicate that the mechanical function is not impaired in significant parts of the lungs, and EFL is only developed in the rest of the parallel compartments [12]. In addition to the full or partial EFL, other mechanisms that cause loop formation should also be considered. Xrs has been shown to be more negative in the presence of inhomogeneous constriction of peripheral airways $[5,6,28,29]$; therefore, the positive change in $X_{\mathrm{rs}}$ during inspiration (addressed later) and its subsequent decrease in expiration must reflect the improvement and impairment in lung homogeneity, respectively. If the decrease in transpulmonary pressure during expiration results in higher peripheral resistances (and increased expiratory heterogeneity), the separation of the inspiratory and expiratory limbs of $X_{\mathrm{rs}}$ will increase the $X_{\mathrm{rs}}$ loop area. Airway wall shunting, whose effect is augmented with increases in peripheral resistance [30], may lead to a more negative Xrs, but again, it is not known how much this mechanism contributes to the AXV. Since all these mechanisms, individually or combined, aggravate the expiration, definition of an accurate EFL threshold value may not be an absolute requirement. We argue that further work in the analysis of these impedance patterns is justified by the multitude of looping patterns observed in this study, as they may be linked to different stages and subtypes of COPD.

Since EFL is the most obvious functional abnormality in COPD, the inspiratory phase of tidal breathing has received little attention in previous investigations focusing on respiratory mechanics in this patient group. The inspiratory $X_{\mathrm{rs}}$ values obtained in our patients with COPD remained below the normal values despite the fact that EFL ceases by the onset of inspiration $[9,31]$. In the presence of emphysematous changes, pulmonary compliance measured in quasi-static conditions exceeds the normal values [32, 33], and hence we would expect more positive $X$ rs values at oscillation frequencies in homogeneous emphysema. However, it is also well established that inhomogeneous obstruction in the lung periphery results in rapid decreases in effective compliance with increasing breathing rate [33,34] or oscillation frequency $[5,22,28,29,35]$. This may explain why the $X_{\mathrm{rs}}$ values are more negative in the COPD subjects, in accordance with the majority of earlier findings $[3,5,7,22,25,35-38]$.

The good temporal resolution of the tracking approach in this study enables a closer inspection of the inspiratory changes in Zrs, and reveals further differences in oscillation mechanics between the healthy subjects and patients with COPD. As a result of the greater mechanical inhomogeneity, $\mathrm{Xr}$ at functional residual capacity in the latter group is distinctly more negative than that of the healthy controls (figure 3 ). During inspiration, $X \mathrm{rs}$ moves in the negative direction in all healthy subjects, due to the increased tone of the respiratory muscles, whereas it uniformly increases in the COPD group, which is most probably due to the improved homogeneity by end-inspiration. A similar difference in the volume dependence of inspiratory $X_{\mathrm{rs}}$ was observed between healthy and wheezy children, and the value of $\Delta X_{\mathrm{I}}$ was suggested as an index of inhomogeneity [10]. However, the fact that the $X_{\mathrm{eI}}$ values in the COPD patients remain significantly lower than in the healthy subjects indicates a certain degree of inhomogeneity not abolished by a normal breath. The lack of improvement in XeI even at high CPAP suggests that its low value might reflect persistent and irreversible alterations in the structure of the respiratory system, and this is also indicated by the similarly pressure-independent values of ReI.

Non-invasive respiratory support improves gas exchange and decreases respiratory muscle work in patients with COPD. However, high intrathoracic pressure has adverse effects on the cardiovascular system and causes discomfort to patients $[39,40]$. Therefore, establishing the minimal pressure in a non-invasive setting that improves respiratory mechanics efficiently is of primary importance [11]. The potential clinical utility of the within-breath $Z$ rs variables defined in the present study was tested during increasing CPAPs

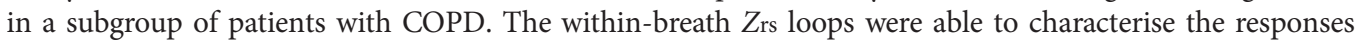
of the respiratory system to the different CPAP levels and revealed large variability in the efficiency of CPAP between individuals (figure 6 and online supplementary figure S4). The changes in AXV and $\Delta X_{\mathrm{I}}$ reflect the improvements in EFL and regional homogeneity, respectively, and they are both linked to various functional abnormalities, such as increased work of breathing, dynamic hyperinflation and impaired gas exchange. Therefore, monitoring AXV and $\Delta X_{\mathrm{I}}$ may be useful to accompany assessments of physiological measures and subjective patient feedback in future research studies.

In summary, the present study introduces a novel aspect of the effort-independent measurement of respiratory mechanics in COPD, by following the cyclic within-breath changes in $Z_{r}$ as functions of tidal volume and flow. This new approach is able to 1) visualise the different patterns of EFL; 2) quantify the degree of inhomogeneous mechanical behaviour of the lungs and its improvement during inspiration; and 3) monitor the impact of CPAP on improving both the EFL and inhomogeneity. Although further investigations are indicated to establish relationships between measures of the within-breath FOT, structural information from lung imaging and clinical symptoms, the proposed non-invasive technique is likely to offer new possibilities in the phenotyping of this complex disease. 


\section{Acknowledgements}

Author contributions were as follows. A. Lorx, Z. Hantos and P.D. Sly conceived the study and designed the measurement principle. D. Bartusek, S. Szigeti, J. Gál and G. Losonczy contributed to the study design, recruited patients and collected data. A. Lorx, Z. Gingl, G. Makan, D. Czövek, B. Radics and Z. Hantos designed the methods of measurement and data processing. A. Lorx, D. Czövek, D. Bartusek, S. Szigeti and B. Radics recorded and evaluated measurement data. A. Lorx, Z. Hantos, D. Czövek and P.D. Sly drafted the manuscript. All authors have seen and approved the submitted manuscript.

\section{References}

1 Global Initiative for Chronic Obstructive Lung Disease. Global Strategy for the Diagnosis, Management, and Prevention of Chronic Obstructive Pulmonary Disease. http://goldcopd.org/global-strategy-diagnosismanagement-prevention-copd-2016/ Date last accessed: June 10, 2016. Date last updated: 2016.

2 Brusasco V, Barisione G, Crimi E. Pulmonary physiology: future directions for lung function testing in COPD. Respirology 2015; 20: 209-218.

3 Crim C, Celli B, Edwards LD, et al. Respiratory system impedance with impulse oscillometry in healthy and COPD subjects: ECLIPSE baseline results. Respir Med 2011; 105: 1069-1078.

4 Koulouris NG, Hradavella G. Physiological techniques for detecting expiratory flow limitation during tidal breathing. Eur Respir Rev 2011; 20: 147-155.

5 Bates JHT, Irvin CG, Farré R, et al. Oscillation mechanics of the respiratory system. Compr Physiol 2011; 1: $1233-1272$.

6 Grimby G, Takishima T, Graham W, et al. Frequency dependence of flow resistance in patients with obstructive lung disease. J Clin Invest 1968; 47: 1455-1465.

7 Zerah F, Lorino AM, Lorino $\mathrm{H}$, et al. Forced oscillation technique vs spirometry to assess bronchodilatation in patients with asthma and COPD. Chest 1995; 108: 41-47.

8 Davidson RN, Greig CA, Hussain A, et al. Within-breath changes of airway calibre in patients with airflow obstruction by continuous measurement of respiratory impedance. Br J Dis Chest 1986; 80: 335-352.

9 Hyatt RE. Interrelationships of pressure, flow, and volume during various respiratory maneuvers in normal and emphysematous subjects. Am Rev Respir Dis 1961; 83: 676-683.

10 Czövek D, Shackleton C, Hantos Z, et al. Tidal changes in respiratory resistance are sensitive indicators of airway obstruction in children. Thorax 2016; 71: 907-915.

11 Dellacà RL, Rotger M, Aliverti $\mathrm{A}$, et al. Noninvasive detection of expiratory flow limitation in COPD patients during nasal CPAP. Eur Respir J 2006; 27: 983-991.

12 Dellacà RL, Santus P, Aliverti A, et al. Detection of expiratory flow limitation in COPD using the forced oscillation technique. Eur Respir J 2004; 23: 232-240.

13 Ohishi J, Kurosawa $\mathrm{H}$, Ogawa $\mathrm{H}$, et al. Application of impulse oscillometry for within-breath analysis in patients with chronic obstructive pulmonary disease: pilot study. BMJ Open 2011; 1: e000184.

14 Aarli BB, Calverley PM, Jensen RL, et al. Variability of within-breath reactance in COPD patients and its association with dyspnoea. Eur Respir J 2015; 45: 625-634.

15 Dellacà RL, Duffy N, Pompilio PP, et al. Expiratory flow limitation detected by forced oscillation and negative expiratory pressure. Eur Respir J 2007; 29: 363-374

16 Johnson MK, Birch M, Carter R, et al. Measurement of physiological recovery from exacerbation of chronic obstructive pulmonary disease using within-breath forced oscillometry. Thorax 2007; 62: 299-306.

17 Mahadev S, Salome CM, Berend N, et al. The effect of low lung volume on airway function in obesity. Respir Physiol Neurobiol 2013; 188: 192-199.

18 Timmins SC, Diba C, Farrow CE, et al. The relationship between airflow obstruction, emphysema extent, and small airways function in COPD. Chest 2012; 142: 312-319.

19 Miller MR, Hankinson J, Brusasco V, et al. Standardisation of spirometry. Eur Respir J 2005; 26: 319-338.

20 Van de Woestijne KP, Franken H, Cauberghs M, et al. A modification of the forced oscillation technique. In: Hutás I, Debreczeni L, eds. 28th International Congress of Physiological Sciences. Akadémiai Kiadó. Budapest, 1981; pp. 655-660.

21 Rabe KF, Hurd S, Anzueto A, et al. Global strategy for the diagnosis, management, and prevention of chronic obstructive pulmonary disease: GOLD executive summary. Am J Respir Crit Care Med 2007; 176: 532-555.

22 Clément J, Làndsér FJ, Van de Woestijne KP. Total resistance and reactance in patients with respiratory complaints with and without airways obstruction. Chest 1983; 83: 215-220.

23 Horowitz JG, Siegel SD, Primiano FP Jr, et al. Computation of respiratory impedance from forced sinusoidal oscillations during breathing. Comput Biomed Res 1983; 16: 499-521.

24 Peslin R, Ying Y, Gallina C, et al. Within-breath variations of forced oscillation resistance in healthy subjects. Eur Respir J 1992; 5: 86-92.

25 Michaelson ED, Grassman ED, Peters WR. Pulmonary mechanics by spectral analysis of forced random noise. J Clin Invest 1975; 56: 1210-1230.

26 Koulouris NG, Valta P, Lavoie A, et al. A simple method to detect expiratory flow limitation during spontaneous breathing. Eur Respir J 1995; 8: 306-313.

27 Ninane V, Leduc D, Kafi SA, et al. Detection of expiratory flow limitation by manual compression of the abdominal wall. Am I Respir Crit Care Med 2001; 163: 1326-1330.

28 Gillis HL, Lutchen KR. How heterogeneous bronchoconstriction affects ventilation distribution in human lungs: a morphometric model. Ann Biomed Eng 1999; 27: 14-22.

29 Kaczka DW, Lutchen KR, Hantos Z. Emergent behavior of regional heterogeneity in the lung and its effects on respiratory impedance. J Appl Physiol 2011; 110: 1473-1481.

30 Mead J. Contribution of compliance of airways to frequency-dependent behavior of lungs. J Appl Physiol 1969; 26: 670-673.

31 Pedersen OF, Butler JP. Expiratory flow limitation. Compr Physiol 2011; 1: 1861-1882.

32 Christie RV. The elastic properties of the emphysematous lung and their clinical significance. J Clin Invest 1934; 13: $295-321$. 
33 Mead J, Lindgren I, Gaensler EA. The mechanical properties of the lungs in emphysema. J Clin Invest 1955; 34: $1005-1016$.

34 Otis $\mathrm{AB}$, McKerrow $\mathrm{CB}$, Bartlett RA, et al. Mechanical factors in distribution of pulmonary ventilation. J Appl Physiol 1956; 8: 427-443.

35 Kaczka DW, Ingenito EP, Body SC, et al. Inspiratory lung impedance in COPD: effects of PEEP and immediate impact of lung volume reduction surgery. J Appl Physiol 2001; 90: 1833-1841.

36 Silva KK, Lopes AJ, Jansen JM, et al. Total inspiratory and expiratory impedance in patients with severe chronic obstructive pulmonary disease. Clinics 2011; 66: 2085-2091.

37 Farré R, Navajas D. Assessment of expiratory flow limitation in chronic obstructive pulmonary disease: a new approach. Eur Respir J 2004; 23: 187-188.

38 Paredi $\mathrm{P}$, Goldman M, Alamen A, et al. Comparison of inspiratory and expiratory resistance and reactance in patients with asthma and chronic obstructive pulmonary disease. Thorax 2010; 65: 263-267.

39 Ambrosino N, Nava S, Torbicki A, et al. Haemodynamic effects of pressure support and PEEP ventilation by nasal route in patients with stable chronic obstructive pulmonary disease. Thorax 1993; 48: 523-528.

40 Ranieri VM, Giuliani R, Cinnella G, et al. Physiologic effects of positive end-expiratory pressure in patients with chronic obstructive pulmonary disease during acute ventilatory failure and controlled mechanical ventilation. Am Rev Respir Dis 1993; 147: 5-13. 